\title{
Ditongos orais e seus processos evolutivos na história do português
}

\author{
Maria José Carvalho \\ Faculdade de Letras da Universidade de Coimbra \\ CELGA-ILTEC (Portugal) \\ mariac@fl.uc.pt
}

Recibido o 07/01/2018

Aceptado o 14/04/2018

(20)

\section{Resumo}

Através do estudo de um corpus medieval (Carvalho 2017), analisam-se, neste artigo, alguns fenómenos de variação e de mudança envolvidos na trajetória histórica dos ditongos decrescentes orais (primários ou secundários) [aw], [aj], [ej] e [ow], salientando-se alguns processos de manutenção, fechamento, redução e criação, no seu percurso evolutivo. Mostra-se como, em algumas unidades lexicais, os ditongos se mantiveram durante todo o período medieval, afastando-se da norma atual (contrauto, p. ex.) e, em outros casos, se registou tardiamente a tendência para a redução, mesmo em formas hoje ditas cultas, que o vieram a recuperar (clasula, p. ex.). Apresentam-se, igualmente, fenómenos de variação -airo/-ario, que poderão contribuir para a complexificação da noção de "cultismo", bem como casos de mudança irreversível, com balizas cronológicas precisas, em formas proparoxítonas (sabham > saibam). No caso de [ej] e [ow], serão fornecidas numerosas abonações que contribuem para fazer recuar a cronologia da monotongação para três ou quatro séculos relativamente à que é referida por Paul Teyssier (1980). Referir-nos-emos, igualmente, à variação oi ui (froyto $\sim$ fruito, por exemplo), existente no galego comum mas com marcos cronológicos delineados (a favor de $u i>u$ ), na nossa coleção. Mostraremos, finalmente, que casos de antecipação de semivogal $w$ (augua) bem como de redução no ditongo crescente wa (agardar), que caracterizam o galego bem como algumas variedades sociais do português, se encontram igualmente representadas nos documentos da zona centro-litoral portuguesa em causa.

\section{Palabras chave}

Dialetologia galego-portuguesa; fonética histórica; ditongos orais; monotongação

\section{Sumario}

1. Introdução: o corpus. 2. Análise do corpus. 2.1. Ditongos decrescentes. 2.1.1. Ditongo [aw] (primário ou secundário). 2.1.2. Ditongo aj secundário. 2.1.3. Ditongo ei e monotongação. 2.1.4. Ditongo ou e monotongação. 2.1.5. Ditongos oi/ui. 2.2. Ditongo crescente [wa]. 3. Conclusões.
Oral diphthongs and their development processes in the history of Portuguese

Abstract

Through study of a medieval corpus (Carvalho 2017), this article analyses some phenomena of variation and change in the historical development of the primary or secondary oral falling diphthongs [aw], [aj], [ej] and [ow], highlighting some phenomena of maintenance, closing, reduction and creation in the course of their evolution. It shows how, in some lexical units, the diphthongs were maintained throughout the medieval period, unlike the current norm (e.g. contrauto), while in other cases a late tendency towards reduction was found, even in forms today considered erudite, which later recovered the diphthong (e.g. clasula). We also look at instances of variation between -airo and -ario which may complicate the notion of what constitutes a "learned word", and cases of irreversible change, with precise chronological endpoints, in proparoxytones (sabham > saibam). In the case of [ej] and [ow], we provide considerable evidence suggesting a chronology for monophthongization three or four centuries earlier than that given by Paul Teyssier (1980). We also touch on the variation oi $\sim$ ui (e.g. froyto $\sim$ fruito), found in common Galician but within a clear chronological framework in our corpus (favouring $u i>u$ ). Finally, we show that cases of anticipation of the semivowel $w$ ( $a u$ gua), and reduction of the rising diphthong wa (agardar), characteristic of Galician and some social varieties of Portuguese, are also found in these documents from the coastal zone of central Portugal.

Keywords

Galician-Portuguese dialectology; historical phonetics; oral diphthongs; monophthongization

\section{Contents}

1. Introduction: the corpus. 2. Analysis of the corpus. 2.1. Falling diphthongs. 2.1.1. The diphthong [aw] (primary or secondary). 2.1.2. The scondary diphthong aj. 2.1.3. The diphthong ei and its monophthongization. 2.1.4. The diphthong ou and its monophthongization. 2.1.5. The diphthongs oi, ui. 2.2 The rising diphthong [wa]. 3. Conclusions. 


\section{INTRODUÇÃO: O CORPUS ${ }^{1}$}

O corpus que iremos analisar é constituído por 153 documentos notariais originais (sécs. XIII-XVI) (Carvalho 2017), oriundo dos fundos do mosteiro cisterciense de Alcobaça, um importante centro na cultura portuguesa medieval (situado na zona Centro-litoral, entre Coimbra e Lisboa). Os documentos situam-se num período compreendido entre 1289 e 1565, e são redigidos não apenas no mosteiro mas também nas áreas periféricas sob sua jurisdição, os chamados "coutos". Escolhemos como amostra um corpus único, seriado cronologicamente, pois cremos que é comparando textos do mesmo género ao longo dos tempos que chegamos ao que Kabatek designou de variação diacrónica "autêntica" (Kabatek 2001: 97). O universo do discurso é a linguagem jurídica usada nos contratos relativos à propriedade: documentos de compra e venda, de arrendamento, de troca, recibos e testamentos, por exemplo. É sobre esta base de campo de estudo - geográfica, cronológica e temática - que podemos observar a evolução contínua dos textos e, por isso, em paralelo, da língua.

\section{AnÁlise do corpus}

\subsection{Ditongos decrescentes}

\subsubsection{Ditongo [aw] (primário ou secundário)}

O ditongo primário [aw], resultante de uma evolução de tipo culto, é extremamente frequente e regista-se ao longo de todo o período estudado, no léxico da linguagem jurídica. Apresentam-se a seguir as ocorrências que nos foi possível encontrar:

\begin{tabular}{|l|c|}
\hline \multicolumn{1}{|c|}{ Formas (e variantes gráficas) } & No de ocorrências \\
\hline autoridade, auctoridade, autorydade, aupterydade, autorjdade, autorridade & 59 \\
\hline audiẽçia, audiencya, audjençias, aud[yẽcy]a, aud[iẽçi]a & 5 \\
\hline auto[r], autor, autores, autoria & 42 \\
\hline caufa, caufas, chau/a, causa & 11 \\
\hline clau/ulas, claufullas, claufolas, claufollas, claufulas, crausollas & 39 \\
\hline
\end{tabular}

Tabela 1. Formas com o ditongo [aw] $(<\mathrm{AU})$

Não obstante as formas acima resultarem de uma evolução culta, conheceram igualmente a evolução de tipo tradicional (semelhante ao resultado geral das palavras que evoluíram por via popular), ou seja, o fechamento e elevação da vogal central nesse ditongo, por assimilação regressiva ([aw] $>[0 w]>[o w])$. Apresentam-se a seguir as abonações encontradas, situadas nos séculos XIV e XV2:

outor (1434 SC 91), outoridade (1345 MA 33) e outorjdade (1410 MA 73).

Por outro lado, quando na mesma palavra existia outro $u$, o ditongo au simplificou-se frequentemente em $a$, por dissimilação. Variantes com monotongação de au primário em $a$ ri-

\footnotetext{
1 Este artigo constitui uma versão muito melhorada de duas secções da tese de doutoramento da autora (Carvalho 2006: 394-403; 409-410), parcialmente inédita. Não serão objeto de estudo neste trabalho os ditongos que se formaram tardiamente, resultantes de síncope de - $d$ - intervocálico nas formas verbais de P5 ou, ainda, os que resultaram de síncope de -L- intervocálico nos plurais dos nomes e adjetivos terminados em l, uma vez que constituem subsistemas específicos, já referidos em outros artigos, de temática diversa (Carvalho 1999 e 2000). Do mesmo modo, sobre a variação entre os ditongos ou oi (muito específica da língua portuguesa), no corpus em apreço, veja-se Carvalho (2011). Também não serão mencionados os casos de formação de ditongo ei ou ou nos grupos iniciais latinos Eks ("ex-"), ECc (com as evoluções paralelas medievais ei-/en-/e-: eixemplo, eigreja) ou occ- (oucidente, por exemplo). A esse propósito, veja-se Carvalho (2015a) e (2015b). ${ }^{2}$ O mesmo tipo de formas é referido por Ferreiro (1999: 70): "é relativamente doado documentar formas evoluídas patrimonialmente que na época moderna recuperaron o ditongo latino (cfr., por exemplo, AUCTŌRİTÃTE > arc. outoridade)".
} 
valizaram durante o período medieval com as que conservaram o ditongo. Tal fenómeno de variação afetou as formas medievais da unidade lexical clausula, que parece ter retomado definitivamente o ditongo apenas a partir dos últimos anos do século XV (no nosso corpus, a partir de 1489). Apresentam-se a seguir as formas registadas com monotongação:

c[r]afulas (1377 Alv 50 e 1380 Alv 52), claffulas (1419 MA 79), claffullao (1478 MA 123, 2 v.; 1479 MA 124 e 1484 MA 126), clafulas (1386 MA 55; 1403 MA 69; 1410 MA 73, 3 v. e 1419 MA 79, 2 v.), clafulla (1430 Cós 89), clafullas (1408 MA 71, 2 v. e 1423 MA 83, 2 v.) e clafullao (1477 MA 121, 4 v.; 1478 MA 122, 2 v.; 1478 MA 123; 1479 MA 124, 2 v.; 1479 MA 124, 2 v. e 1485 MA 128).

O mesmo aconteceu com crafta (< CLAUSTRA-) 'claustro' (1428 MA 87; 1490 MA 131) e sobre craftas (1521 Ped 143).

Indica-se a seguir o número de ocorrências de au secundário, ou seja, quando resulta da vocalização de $k$ ou $p$ dos grupos -kT- ou -PT- precedido de $a$ :

\begin{tabular}{|c|c|}
\hline Formas (e variantes gráficas) & Número de ocorrências \\
\hline  & 16 \\
\hline aucto, autoall, autos, auto & 18 \\
\hline $\begin{array}{l}\text { contrauto, [cõ]trauto, [con]trauto, [con]t[r]auto, [cõ]t[r]auto, cont[r]auto, } \\
\text { cõt[r]auto }\end{array}$ & 23 \\
\hline trautada, trauta & 2 \\
\hline 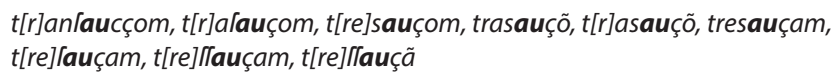 & 14 \\
\hline Bautifta e Bautylta & 6 \\
\hline
\end{tabular}

Tabela 2. Formas com o ditongo au (<a+ vocalização do $1^{\circ}$ elemento de -KT- ou -PT-)

A evolução de tipo tradicional também se regista, ainda que excecionalmente, nas formas com ditongo secundário: ouçõ (1366 MA 46).

No que diz respeito à atual forma contrato, com ditongo au secundário no português medieval, a monotongação a que se aludiu acima deve ter sido posterior à Idade Média, pois nunca se regista ao longo do período estudado. Uma pista para o estabelecimento dessa cronologia poderá ser a forma tardia tratou, que se pode observar no último documento do corpus: tratou (1565 Alc 153), embora não possa afastar-se a possibilidade de se tratar de uma solução semiculta.

Importa salientar que, excecionalmente, num dos primeiros documentos em que aparece aquela unidade lexical, verifica-se a variante cõtrayto (1416 MA 78, 2 v.), o que prova que a vocalização do primeiro elemento do grupo -KT-, quando precedido de $a$, pode ter dado origem a $a i$, mas esse tratamento, em que $k$ se vocaliza em [j], não ultrapassou nesta unidade lexical a percentagem de $5 \%$.

\subsubsection{Ditongo aj secundário}

$\mathrm{Na}$ fase mais antiga da língua podem registar-se as formas etimológicas quayrela (1315 Alj 15, 2 v.) e cayrela (1315 Alj 15), resultantes da vocalização do primeiro elemento do grupo consonântico -DR- (< QUADRELLA). Com o decorrer do tempo, o primeiro elemento vocálico tendeu a fechar-se, transformando-se em vogal posterior, eventualmente por influência da consoante velar: coyrela é, assim, a forma mais frequente, tendo o ditongo oi sido posteriormente substituído por $\mathrm{ou}^{3}$.

Segundo Clarinda Maia, "em palavras cultas, não tradicionais, originariamente terminadas em -ARIU, o resultado mais frequente nos textos da Galiza é -ario (...). Pelo contrário, nos documentos

${ }^{3}$ Sobre a variação ou oi no período medieval, veja-se Carvalho (2011). 
da região portuguesa predominam formas com atração da semivogal para a sílaba tónica" (Maia 1997²: 541-542).

São os seguintes os exemplos encontrados nos documentos da nossa coleção em que, depois da atração da vogal para junto da sílaba tónica, não se completa a evolução de ai para ei:

[cõ]t[r]airo (1438 Ped 95), [cõ]trairo (1482 MA 125), [con]t[r]airo (1428 MA 87), [cont]r[a]iro (1426 MA 85), contrairo (1515 SM 141), contrayro (1487 PP 129), deluairo (1402 MA 67), delvayro (1467 Mai 117), ffamiliayro (1307 Alp 13), ffamyliayro (1307 Alp 13)4, hordenairo (1430 Cós 89 e 1448 Alj 103), hordenayro (1496 Sal 135), hordenayroo (1467 Mai 117), hordjnairo (1405 MA 70), hordjnhairo (1402 Ped 68), notairo (1478 MA 122), notayro (1490 MA 131), ordenairo (1515 SM 141), ordenairos (1521 Ped 143), ordenayro (1487 PP 129; 1532 Tur 149), ordinhayros (1379 Alc 51), ordjnhayro (1379 Alc 51), tríjntayro (1343 AM 31), trintairos (1422 MA 81, 2 v.), uigajro (1352 Ped 38), uigayro (1289 MA 1 e 1300 Alj 8), ujgajro (1435 Alj 92; 1437 Ped 94), veltiayro (1304 Alc 10, 2 v.), vigairo (1472 TC 120, 2 v.), vigayro (1297 Cos 4, 2 v.; 1304 Alc 10 e 1338 Alv 28), viguairo (1402 MA 67), vjgairo (1435 Alj 92 e 1455 MA 108) e vygayro (1491 Alj 133, 4 v.).

O resultado -ario regista-se em duas classes de palavras:

i. Em alguns nomes de cargos ou profissões:

comendatario (1527 MA 146), comy Ifaryo (1430 Cós 89), donatarios (1536 SC 150), donataryos (1536 SC 150,2 v.) e secretarjo (1532 Tur 149).

ii. Nas variantes gráficas do adjetivo necessário:

neleçario (1522 MA 144), neçeçaryo (1491 Alj 133), neçesarias (1529 MA 148), neçesario (1529 MA 148), neçelarías (1336 Alj 26), neçelario (1372 MA 47; 1422 MA 82; 1425 MA 84), neçelaryo (1519 MA 142) e neçelfareo (1482 MA $125 ; 1536$ SC 150).

As abonações apresentadas colocam-nos perante a questão de saber o que deverá considerar-se uma "evolução de tipo culto, não tradicional". De facto, se a estrutura acentual da palavra fosse o único critério para o estabelecimento da definição, teríamos formas polissílabas, sem atração, como (h)ordenario, familiario, o que não acontece. Por outro lado, se o aliarmos a critérios semânticos, poderíamos ser levados a considerar que apenas os nomes de cargos e profissões com mais de três sílabas caberiam nessa tipologia. A verdade é que ocorre sistematicamente a variante do adjetivo neçelario (sem atração), que não se enquadra nessa tipologia.

Um aspeto particularmente importante para questões de periodização prende-se com a formação do ditongo ai na atual forma de presente do conjuntivo saibam. No segundo quartel do século XV regista-se o fenómeno de variação, sendo um documento escrito em Alvorninha, em 1450, o último reduto de sabham. A repartição das formas referidas é a seguinte:

\begin{tabular}{|l|c|l|}
\hline \multicolumn{1}{|c|}{ Cronologias } & Número de ocorrências & \multicolumn{1}{c|}{ Forma } \\
\hline $1297-1386$ & 38 & sabhã \\
\hline $1345-1435$ & 15 & sabhãm \\
\hline $1350-1450$ & 26 & sabham \\
\hline
\end{tabular}

Tabela 3. Repartição das formas do Presente do conjuntivo do verbo saber, sem formação de ditongo

O h com valor fónico de [j] manteve-se até cerca do primeiro quartel do século XV na forma sabham (< SAPİANT) e variantes gráficas ${ }^{5}$, mas a partir de 1423, essa semivogal é atraída para a sílaba tónica, formando com a vogal dessa sílaba o ditongo decrescente $a i^{6}$.

\footnotetext{
${ }^{4} \mathrm{O}$ mesmo nome volta a surgir mais tardiamente na variante atual: "Johãm Martjz famjliar" (1467 Mai 117).

${ }^{5}$ De modo completamente isolado, atesta-se sabbã no primeiro documento desta coleção (1289 MA 1).

${ }^{6}$ Por vezes, o $h$ mantém-se a partir dessa altura no mesmo contexto, muito provavelmente por hábito gráfico, dando origem a formas do tipo saibham. A esse propósito, refere José Joaquim Nunes: “Neste verbo [saber], como em caber, aparece nos documentos antigos também saibia e caibia, formas estas que me parecem puramente gráficas, devidas ao cruzamento entre saiba [sic], cabia e saiba, caiba" (Nunes 1989": 331, nota 2).
} 
Apresentam-se a seguir os exemplos do corpus, localizados em documentos posteriores a essa data":

saibam (1459 MA 111; 1460 MA 112), saibhã (1426 MA 85; 1455 MA 108), saibham (1423 MA 83; 1436 Alf 93; 1438 Ped 95; 1442 SM 97; 1444 Alv 100; 1447 Alj 101; 1448 Alj 103; 1456 MA 109; 1478 MA 123; 1482 MA 125; 1490 MA 131; 1527 MA 146; 1528 MA 147; 1529 MA 148), saibhäm (1437 Ped 94; 1440 MA 96; 1443 Alf 99; 1459 MA 110; 1471 MA 119; 1477 MA 121; 1478 MA 122; 1478 MA 123; 1479 MA 124; 1484 MA 126; 1484 MA 127; 1485 MA 128; 1502 MA 137; 1505 MA 138; 1507 MA 139), sajbam (1448 Ped 102), sajbham (1491 Alj 132), sajbhãm (1491 Alj 133), saybam (1442 MA 98; 1469 Cel 118; 1487 PP 129; 1509 Ped 140), saybham (1462 Alj 115; 1495 MA 134; 1496 Sal 135; 1515 SM 141; 1519 MA 142; 1521 Ped 143; 1522 MA 144; 1536 SC 150; 1536 SC 151), saybhãm (1462 Mai 114; 1467 Mai 117; 1489 MA 130; 1500 MA 136; 1532 Tur 149); saybhão (1541 Sal 152) e laibham (1526 Ped 145).

A propósito das mesmas formas, na primitiva região galego-portuguesa, exprime-se deste modo a autora de HGP:

aparecem diferentes tipos de variantes, umas extensivas a toda a área galego-portuguesa, outras restritas apenas aos documentos da Galiza. As formas de feição mais antiga são aquelas em que a semivogal se mantém depois da consoante b: elas surgem, em geral, durante o século XIII e primeira metade do século XIV, só ultrapassando excepcionalmente este período (...). Das formas de feição mais recente, com atracção, encontram-se alguns exemplos em documentos portugueses do século XV, embora com carácter esporádico: saibam (1416 M 168), sajbam (1484 DL 150) (Maia 19972: 809).

O mesmo fenómeno de atração pode observar-se na forma elcaybar 'trocar' (< ${ }^{*}$ EXCAMBIĀRE) e no nome deverbal elcaybo. A primeira forma encontrada com atração da semivogal data de 1402: elcaybar (1402 Ped 68), mas a variante que dominou a primeira metade do século XV foi a antiga, sem atração. Podem encontrar-se os seguintes exemplos: elcãbhar (1321 Alc 17; 1324 Alc 18), Icanbhar (1388 MA 58; 1397 MA 63; 1397 MA 64; 1399 MA 66; 1403 MA 69; 1408 MA 71; 1410 MA 73; 1413 MA 75), Icãbhar (1430 Cós 89) e ellcãbhar (1450 Alv 104).

Só a partir do $3^{\circ}$ quartel do mesmo século os exemplos evidenciam sistematicamente o ditongo $a y^{8}$, por vezes nasal, em virtude da manutenção da nasalidade na sílaba pretónica:

elcaimbar (1528 MA 147), elcajmbar (1460 MA 112), elcaybaar (1500 MA 136), elcaybar (1478 MA 122; 1478 MA 123; 1479 MA 124; 1485 MA 128; 1489 MA 130; 1495 MA 134; 1502 MA 137; 1505 MA 138; 1507 MA 139), elcaybo (1471 MA 119, 6 v.) e Icaibar (1484 MA 126).

Na forma reparar (< RËPĂRĀRE) e variantes (derivadas e flexionais), desenvolve-se a semivogal [j] seguida da vibrante $r$. Estas formas são usadas de modo exclusivo ao longo deste corpus ${ }^{9}$. Vejamos os exemplos que extraímos:

repairar (1459 MA 111), rrepairadas (1528 MA 147), rrepairamento (1423 MA 83), rrepairaredes (1465 MA 116), rrepairarem (1479 MA 124), rrepairalfem (1422 MA 82), rrepaire (1522 MA 144, 2 v.; 1528 MA 147), rrepairedes (1397 MA 64), rrepairem (1422 MA 82; 1478 MA 123; 1479 MA 124), rrepairen (1482 MA 125), rrepairredes (1383 Alj 53), rrepayra[r]m[os] (1452 MA 106), rrepayradas (1452 MA 106), rrepayrando (1478 MA 122), rrepayrar (1519 MA 142), rrepayraram (1479 MA 124), rrepayrardes (1419 MA 79), rrepayraredes (1453 MA 107) e rrepayredeo (1478 MA 122).

Finalmente, revela-se complexa a forma de origem árabe alcade ("dom Pedro, alcade de Maçeira", 1375 MA 49) uma vez que ocorre sem semivogal, de modo completamente isolado. Representa apenas $8 \%$ num universo de 12 ocorrências da unidade lexical:

alcaide (1430 Cós 89 e 1522 MA 144) e alcayde (1306 Cós 12; 1329 Evo 22; 1338 Alv 28; 1340 Ped 29, 2 v.; 1436 Alf 93, 2 v.; 1437 Ped 94 e 1491 Alj 132).

De facto, segundo Ramón Lorenzo (1977), alcayde é derivada de AL-QĀ 'ID enquanto que alcaide de AL-QĀDİ, ambas árabes. Torna-se impossível saber, portanto, se a forma citada apresenta

\footnotetext{
7 De salientar, todavia, que a forma sabbãm, hoje popular, "emparelhando com cabam, valam, habam, por influência do infinitivo" (Nunes: 331, nota 2) atesta-se no documento 1430 Cós 89 . Por outro lado, o único documento a evidenciar a forma sabham após a referida data é de 1450 e foi escrito em Alvorninha, reduto linguístico que conservou até mais tarde as formas antigas, como temos vindo a referir.

${ }^{8}$ Uma forma tardia revela o desenvolvimento da semivogal em sílaba tónica: elquambairẽ (1522 MA 144).

${ }^{9}$ Segundo Ramón Lorenzo (1977), a forma antiga repairar documenta-se a partir do século XIV. Vejam-se as abonações por ele apresentadas em La traducción gallega de la Crónica General y de la Crónica de Castilla, vol. II, (Glosario), s. u. "reparar".
} 
a monotongação de ai, ou se é apenas o representante histórico de AL-QĀDİ, denunciando, assim, uma outra solução, sem ditongo.

\subsubsection{Ditongo ei e monotongação}

Este tipo de ditongo está contido nas formas meyado (1343 AM 31) e meyo (1321 Alc 17; 1324 Alc 18; 1343 AM 31, 2 v. e 1352 Ped 38; 1415 Ped 77, 3 v.), mas a partir de finais do século XIV começam a surgir as formas meo (1392 MA 60; 1472 TC 120; 1505 MA 138) e mea (1528 MA 147, 2 v.), que prevalecem no século XVI.

A semivogal em posição interior desapareceu definitivamente da forma meyadade (1291 Alc 3, 2 v.; 1332 Alc 24; 1388 MA 58; 1399 MA 65), a partir do século XV. De facto, nos últimos anos do século XIV, essa forma rivaliza com meatade (1372 MA 47, 2 v.; 1377 Alv 50, 3 v.; 1380 Alv 52, 2 v.), que se encontra também nos primeiros anos do século XV (1402 Ped 68, 5 v.; 1415 Ped 77, 4 v.). Saliente-se, todavia, que no documento de 1402, ao lado das 5 ocorrências de meatade, convive a forma, já idêntica à atual, metade (1402 Ped 68). Assim, a partir da segunda metade do século $\mathrm{XV}$, encontra-se em variação a forma com assimilação de $a$ e aquela que revela o resultado da crase: meetade (1465 MA 116, 2 v.; 1485 MA 128, 2 v.) e metade (1450 Alv 104, 2 v.; 1507 MA 139, 2 v.). Na coleção de $H G P$, "a supressão da semivogal só muito raramente se registou nos textos de Portugal" (Maia 1997²: 622).

Esperança Cardeira admite que

da análise destes segmentos vocálicos não releva uma tendência evolutiva nítida: se o iode anti-hiático surge já representado desde o último quartel do século XIV, durante todo o século XV o seu uso não aumenta significativamente, continuando as formas cuja grafia representa o tritongo a alternar, esporadicamente, com as sequências de grafia hiática, mais numerosas (Cardeira 2005: 275).

Baseando-se no gráfico ilustrativo da sequência -eo/-eio no conjunto da documentação por ela estudada, e que inclui meo meio, conclui que "a grafia que representa o tritongo nunca chega a atingir $30 \%$ do total; a partir do segundo quartel do século XV a sua frequência tende a aumentar, embora esse acréscimo seja pouco significativo" (Cardeira 2005: 275). De qualquer forma, acrescenta:

mas note-se que a inclusão, nestes totais, das variantes meo meio, aumenta bastante a frequência das grafias com iode; do seu expurgo, entre 1425 e 1450, resultam as percentagens 1\% na documentação notarial, $0 \%$ nas Vidas de Santos e 3,7\% no Livro da Cartuxa. Estes resultados denotam, afinal, a adopção, no texto de D. Duarte, da inovação, e revelam a importância da variação meo meio nos textos não literários: a sua frequência pode ter contribuído para a aceitação do tritongo em formas em que foi inserido um iode anti-hiático (Cardeira 2005: 276).

Sem questionar o rigor da análise de Cardeira perante os dados que possui, parece-nos, contudo, que, em face do corpus de que dispomos ("coerente", do ponto de vista dialetal e tipológico, bem como cronologicamente seriado), deverá aceitar-se a possibilidade de formas como meyo terem resultado da evolução do étimo ME(D)ıO, após a síncope de consoante intervocálica. Formas deste tipo poderão ter sido as que ofereceram eventualmente o contexto mais propício à monotongação, fenómeno que foi posteriormente estigmatizado.

A forma de origem árabe aldeya, generalizada, no nosso corpus, no século XIV (1321 Alc 17; 1328 Alv 20; 1343 AM 31, 2 v. e 1359 MA 42, 2 v.), surgirá sem semivogal num documento do século XV: aldea (1453 MA 107, 2 v.), mas num documento tardio, onde ocorre 2 vezes a forma mea, volta a recuperá-la: al[de]ia (1528 MA 147). De acordo com Ramón Lorenzo:"las formas con -i- no son continuación del diptongo árabe. Deben mirarse como formas con -i- antihiática (cfr. area $>$ areia, cheo > cheio, etc.). La forma hoy normal en Portugal es aldeia; aldea se conoce como regionalismo septentrional y es la típica del gall." (Lorenzo 1977: s. u. "aldea", "aldeia", "aldeya"). Segundo Veiga Rodríguez,

Nos exemplos medievais de aldeia/aldeya si podemos ve-lo resultado normal - ainda inalterado - do ditongo árabe ai, pero non no resultado portugués aldeia, que se debe a un proceso diferente e posterior, onde, de acordo coa tendencia xeral na fonotáctica iberorromance, o iode abre sílaba, polo que, frente á posible realidade dos exemplos arcaicos, non se trata dun caso de ditongo ei, senón dunha silabación al-de-ia (Veiga Rodríguez 1986: 305). 
De facto, recordando os testemunhos apresentados referentes ao nosso corpus, podemos constatar que a esmagadora maioria das abonações para aldeya (6 ocorrências) situa-se na primeira metade do século XIV, o que, nesta fase, nos faz pensar no resultado normal do ditongo árabe $a i$, à semelhança do que aconteceu no galego.

O ditongo ei pode provir de $\mathrm{E}+\mathrm{SI}$, tendo a palatalização deste grupo sido acompanhada do desenvolvimento de semivogal palatal, tal como ainda subsiste no galego: Tareixa ${ }^{10}$. Nos documentos sob análise encontra-se abundantemente representado esse tratamento, sendo exclusivo no antropónimo correspondente ao atual Teresa: Tareija (1328 Alj 21); Tareyia (1343 AM 31; 1362 MA 43, 2 v.; 1413 MA 75, 2 v.) e Tareyja (1452 MA 106).

Está ainda presente na terminação -eiro/- $a$, muito frequente ao longo do período medieval, quer se trate da evolução de A + RI (primeyro, ribeyro, celareyro, etc), de E + RI (moelteyro, madeira, etc.), quer, ainda, de derivados como pelfoeiro ("E o filho mayor leia pelloeiro pera tirar os nolos foros e nolos ẽtregar", 1375 MA 48) ou ualledeira (1388 MA 57) e ualedeyra (1388 MA 57; 1399 MA 65, 2 v.).

Quanto à questão da monotongação de ei, podemos dizer que começa a revelar-se em documentos redigidos no mosteiro situados já no $3^{\circ}$ quartel do século XIV ${ }^{11}$, e torna-se bastante frequente num documento tardio, dos primeiros anos do século XVI, escrito em S. Martinho. Apresentamos a seguir os dados que foi possível obter relativamente a essa monotongação, que se verifica sobretudo quando ei vem seguido de fonema fricativo pre-palatal, alveolar ou ainda em sequências vocálicas (me-io):

\begin{tabular}{|l|l|}
\hline \multicolumn{1}{|c|}{ Cronologias } & \multicolumn{1}{|c|}{ Formas } \\
\hline 1362 MA 44 & lexar \\
1363 MA 45 & lexar \\
1392 MA 60 & meo \\
1402 MA 67 & ferero; camarero \\
1419 MA 79 & lexar \\
1453 MA 107 & aldea, 2 v. \\
1472 TC 120 & meo \\
1505 MA 138 & meo \\
1515 SM 141 & pexe (7 v.), pexes; Viera \\
1528 MA 147. & mea, 2 v. \\
\hline
\end{tabular}

Tabela 4. Formas que evidenciam a monotongação de ei

Convém mencionar que no documento 1362 MA 44 são as seguintes as formas com ei: azeite (2 v.), carniceyro, colheyto, d[ere]itos (2 v.), ff[r]ey, maneyra; oliueyras, p[re]yto; poltumeyra, poltumeyro, proueytardes (2 v.) e proueytedes. No documento 1363 MA 45, escrito pela mesma mão, encontram-se: Eyrea, frey, madeyra, preyto, proueytardes e Ribeyra. No documento 1419 MA 79 observam-se as seguintes formas: ap[ro]ffeytardes, azeite, azejte, colheito, deradeiro, eira (2 v.), enteiramẽte, exeiçom, ffrey (3 v.), Janeiro, moefteiro, oljueiras (6 v.), p[o]rteiro, proffeytardes, Rey e rrendeiro. Finalmente, o documento 1515 SM 141 apresenta: ap[ro]ueitar, azeite (4 v.), Eytor, hap[ro]ueitar (2 v.), Janeiro, leira, Pederneira (2 v.), Rey (10 v.), ley, verdadeira e Vieira (2 v.).

Ainda que os exemplos recolhidos se encontrem, na generalidade dos casos, relativamente isolados, uma conclusão se pode extraír com alguma segurança: a monotongação deve ter encontrado um contexto propício quando o ditongo ei vem seguido de fricativa palatal surda (graficamente, $x<-x$ - ou I + -sc-). Esperança Cardeira e Maria Alice Fernandes chamaram perti-

\footnotetext{
${ }^{10}$ De acordo com Boullón Agrelo (1999: 425), "é um dos 15 nomes femininos máis frecuentes en Galicia no séc. XIII". De entre as 17 abonações que apresenta, a autora refere Tareiga (regina domina) 12.1132 8s. 13) CDXubia 78, bem como Tareisa (domna) [filla do rei Afonso VI] 12. [1125-45] Tsamos 257; também (com outro epíteto) Tareisa Adefonsi 12.1125 Tsamos 160. ${ }^{11}$ De acordo com Jorge Manuel de Morais Gomes Barbosa, na Crónica de Castela, "a semivogal é absorvida pela palatal seguinte em bejar" (Barbosa 1958: vol. I, 61).
} 
nentemente a atenção para este tipo de contexto, referindo-se à forma pexoteiro (1394), que surge num documento algarvio:

A forma pexoteiro pode ser associada a exemplos, mais ou menos singulares, de monotongações bastante antigas. Basta lembrar a oscilação lexar lecxasẽ presente na Notícia de Torto, ou beigio beio, no Testamento de D. Afonso II. Esta alternância pode ser interpretada como uma monotongação condicionada pela palatal seguinte ou como um mero recurso gráfico (...). Se aceitarmos a hipótese da monotongação, então teremos de admitir que pexotero possa continuar uma tendência já antiga do português arcaico, no sentido da redução do ditongo condicionada pelo contexto consonântico (Cardeira / Fernandes 1997: 61).

De facto, mais de metade dos exemplos apresentados encontra-se nessas circunstâncias, sendo a monotongação de ei nesse contexto um traço idioletal da pessoa que redige os documentos do século XIV, eventualmente um clérigo-notário. Não deixa de se revelar significativo o documento 1402 MA 67, que evidencia as formas ferero e camarero (<-ARIU), uma vez que, se excetuarmos as formas monossilábicas Rey e $f[r e]$, que nunca apresentam a redução do ditongo (pelo menos no texto escrito), apenas rivalizam com preito (2 v.) e feitura, cuja semivogal resultou da vocalização do primeiro elemento do grupo -kT-. Assim, se apenas tivermos em conta as formas resultantes de -ARIU, estas últimas formas representam 100\%; se, pelo contrário, considerarmos também as que resultaram daquela evolução, ferero e camarero ocupam $40 \%$. Por último, no documento quinhentista, escrito em S. Martinho, a monotongação torna-se exclusiva na forma com a procedência İ + -sc- (PİSCES), mas o apelido Viera convive com Vieira (2 v.), verificando-se outras formas com ditongo ei, com diferentes proveniências.

Os dados aduzidos ajudam, assim, a esclarecer o problema da cronologia da monotongação de ei, referido por Paul Teyssier. Relembre-se que, de acordo com o linguista francês,

il est difficile de préciser à quelle date s'est produite, dans le sud du pays, la monophtongaison de ei. Dans le théâtre populaire de la seconde moitié du XVIII siècle, e au lieu de ei caractérise le parler des personnages populaires de l'Alentejo, ex. sardinhero pour sardinheiro. La monophtongaison était donc un fait acquis à cette date. Mais il est possible que ses premières manifestations soient plus anciennes (Teyssier 1980: 80).

Recorde-se que, segundo Ivo Castro, do português clássico ao português setecentista, o ditongo [ẹi] monotongou-se em /e/ "nos dialectos de uma região tão meridional que não chegou a abranger a variante de Lisboa" (Castro 1991: 257). Como se sabe, ao contrário do que acontece com a monotongação de ou, este fenómeno não foi admitido na língua comum, o que permite rotulá-lo como "marcado" no português atual.

\subsubsection{Ditongo ou e monotongação}

Retomando as considerações de Paul Teyssier:

La diphtongue ou, c'est-à-dire [ọw], est devenue aujourd'hui [ọ] dans le portugais commun, ex. cousa, pouco, amou, doutor. Cette monophtongaison a sans doute commencé à se manifester au XVII siècle. Elle a envahi tout le sud et la plus grande partie du centre du Portugal, mais dans tout le reste du pays, c'est-à-dire encore une fois au nord, l'ancienne diphtongue ou ([ọw]) reste vivante. (...) Nous constatons encore une fois, avec cette monophtongaison, qu'une innovation venue du sud s'est imposée au portugais commun et a repoussé vers le nord l'usage ancien en le marginalisant (Teyssier, 1980: 65).

E, em outro passo, acrescenta que «a la monophtongaison de ou en [ọ] fait pendant, à partir d'une date qu'il est difficile de déterminer, la monophtongaison de ei en [ẹ]» (Teyssier 1980: 79).

Seja qual for a procedência histórica do ditongo ou, a verdade é que desde finais do século XIII, mas mais intensamente a partir do último quartel do século XIV, o nosso corpus apresenta manifestações gráficas que sugerem uma tendência, eventualmente de origem rústica, para a monotongação de ou ${ }^{12}$. As abonações que possuímos são bastante mais numerosas do que as que evidenciam a monotongação de ei em [ẹ] e encontram-se sistematizadas na tabela seguinte:

\footnotetext{
${ }^{12}$ Tenha-se em conta que cerca de metade destes documentos são oriundos de zonas periféricas ao mosteiro, muito pouco representadas no nosso corpus.
} 


\begin{tabular}{|c|c|}
\hline Cronologias & Formas $^{13}$ \\
\hline 1291 Alc 2 & collas $\sim \operatorname{coula~(3~v.)~}$ \\
\hline 1315 Alj 15 & ouirẽ \\
\hline 1375 MA 48 & Orẽ; colas $^{16} \sim$ coulas (4 v.); coula \\
\hline 1383 Alj 53 & colas $\sim$ coullas (7 v.); coulla \\
\hline 1392 MA 60 & troueltes $\sim$ trouveram \\
\hline 1396 Ped 62 & palo ${ }^{17}$ \\
\hline 1419 MA 79 & oujdor ouuirdes; louou \\
\hline 1428 Alj 86 & telorejro tellourejro \\
\hline 1437 Ped 94 & Otubro ${ }^{18}$ \\
\hline 1451 MA 105 & odiencyas $\sim$ audiencya \\
\hline 1452 MA $106^{14}$ & ovidor \\
\hline 1453 MA 107 & oujdor ouujdor; ouujrdes \\
\hline 1462 Mai $114^{15}$ & ap[ro]uer \\
\hline 1467 Mai 117 & ap[ro]uer, 3 v.; ap[ro]uelle \\
\hline 1482 MA 125 & otorgarom; otorgaua \\
\hline 1485 MA 128 & do $\sigma \sim d o u \sigma$ \\
\hline
\end{tabular}

Tabela 5. Formas que evidenciam a monotongação de ou

Na forma ouirẽ (1315 Alj 15), deverá admitir-se a possibilidade de $u$ poder representar a semivogal do ditongo (em formas primitivas, sem desenvolvimento da consoante / $/$ / anti-hiática). O mesmo se aplica à forma louou do documento 1419 MA 79. Segundo Ramón Lorenzo, quanto a loar, "al contrario del gall., es ya muy rara esta forma en textos ports. del XIV, pues desde el XIII se usa louuar" e "la forma gall. oír es común al port. del XIII" (Lorenzo 1977: s. u. "oyr", "ouyr", "ouuir", “loar", “louar", “louuar").

Em todas as restantes ocorrências desta coleção, e ao longo do leque cronológico abrangido pelo presente estudo (desde os textos do século XIII), encontra-se representada a consoante anti-hiática: louuafem (1 v.), louuamolo (2 v.), louuamos (28 v.), louuarõ/louuarã/louuaram (9 v.), lounaua (1 v.), louuo (6 v.), louuor (1 v.), louuou (2 v.), ouuir (3 v.), ouuirẽ (5 v.), ouuiriã (1 v.), ouujdo (1 v.), ouujdor (35 v.), ouujdores (2 v.), ouujdoria (2 v.), ouujr (4 v.), ouujle/ouujlem (2 v.), ouuydor (1 v.), ouvjram (4 v.).

No sentido de tornar mais nítidos os contornos cronológicos da monotongação deste e do ditongo anteriormente estudado, interessa referir que no documento 1419 MA 79, para além de oujdor e louou, se encontra a forma lexar, que consta na tabela 4. Estes dados permitem, assim, afirmar que a monotongação destes dois ditongos era já uma realidade no primeiro quartel do século XV, pelo menos no idioleto de alguns tabeliães. No documento em questão, trata-se de "Johãm Anes", "tabeliam por El Rey no dicto moefteiro e geeral nos coutos dell".

\subsubsection{Ditongos oilui}

\section{Segundo a autora de HGP:}

a coexistência, na Galiza, de formas com [ọi] e com [ui] durante o período medieval teria levado à alternância desses dois ditongos e à generalização dessa alternância a palavras que tinham originariamente o ditongo ui, formado por vocalização de $k$ do grupo -KT- precedido de $u$ (< ū do latim clássico). E, assim, pelo menos desde o século XIII e princípios do século XIV, se encontram os dois tipos de variantes (Maia 19972: 558-559).

\footnotetext{
${ }^{13}$ Incluímos na tabela as outras variantes (por vezes flexionais) do mesmo lexema, presentes no mesmo documento, no caso de existirem.

${ }^{14}$ Deverá atribuir-se à mesma mão o documento seguinte.

${ }^{15} \mathrm{O}$ tabelião é o mesmo que escreve o documento seguinte, também em Maiorga ("Aluaro Fferrnãdez").

${ }^{16}$ Esta forma está inserida na expressão final, exterior ao texto: “Aqui cõ tudo tirado pã e uinho que he ao quarto e todas colas que Deus der no dito calal".

${ }^{17}$ Trata-se de uma leitura duvidosa; o contexto deixa entrever a 3 a pessoa do singular do Pretérito perfeito.

${ }^{18} \mathrm{Um}$ documento mais tardio apresenta a forma Utubro (1505 MA 138), revelando duas etapas: a monotongação e posterior fechamento da vogal posterior média.
} 
Acrescenta, mais adiante, ao referir-se à situação linguística dos documentos portugueses por ela selecionados:

Em palavras com a mesma proveniência os documentos de Portugal oferecem de modo habitual formas com ui, o que se compreende facilmente uma vez que, como vimos, no caso de palavras em que existia ọi proveniente do encontro de $o$ com $i$ resultante da vocalização de $k$ do grupo -KT- ou de $/$ do grupo -LT-, desde o século XIII que a língua começa a fixar-se nas formas inflexionadas com ui, não se tendo criado esse estado de flutuação fonética entre os dois ditongos que existiu a norte do Minho. Sendo assim, não se generalizou a alternância ou/ui a formas que tinham inicialmente este último ditongo. Apenas num documento outorgado em Valença registei a forma froytos (1416 M 168), certamente por influência das variedades vizinhas de além-Minho (Maia 19972: 559).

A análise do nosso corpus revela, no entanto, que essa alternância se generalizou, na área que nos ocupa, pelo menos até cerca de 1450. Referimo-nos à forma historicamente resultante de FRŪCTU- e seus derivados, que conheceu desde cedo as formas com oi:

\begin{tabular}{|c|c|c|c|}
\hline \multicolumn{2}{|c|}{ Variantes com oi } & \multicolumn{2}{|c|}{ Variantes com ui } \\
\hline Documentos & Formas & Documentos & Formas \\
\hline & & 1291 Alc 2 & frutefegedel \\
\hline & & 1291 Alc 2 & fruytos \\
\hline & & 1291 Alc 3 & frutiuiguedel; fruytol \\
\hline & & 1297 Alc 5 & fruytos, $2 \mathrm{v}$; fruyta; fruyto, $2 \mathrm{v}$. \\
\hline 1304 Alc 9; & froytos & & \\
\hline 1304 Alc 10 & froytos, $2 \mathrm{v}$. & & \\
\hline 1315 Alj 15 & froyto & & \\
\hline 1317 Alc 16; & froytos & 1317 Alc 16; & frutifiguedel \\
\hline 1321 Alc 17 & froytedes & 1321 Alc 17 & fruytos \\
\hline \multirow[t]{2}{*}{1321 Alc 17} & froyta & & \\
\hline & & 1324 Alc 18 & frutiffigardes; frutifig[ue]des \\
\hline 1337 Alc 27 & froytiuigar & 1337 Alc 27 & fruytos \\
\hline 1337 Alc 27 & froytiuigardes & & \\
\hline \multirow[t]{4}{*}{1346 Tur 35} & froytos & & \\
\hline & & 1359 MA 42 & fruytos \\
\hline & & 1372 MA 47 & ffrujtos \\
\hline & & 1379 Alc 51 & frut[os] \\
\hline \multirow[t]{5}{*}{1383 Alj 53} & frojtos & & \\
\hline & & 1397 MA 63 & frujtas, $2 \mathrm{v}$. \\
\hline & & 1422 MA 82 & fruyt[os] \\
\hline & & 1429 MA 88 & frujtos \\
\hline & & 1438 Ped 95 & [huIfo] frujto \\
\hline \multirow[t]{8}{*}{1450 Alv 104} & ffroytas; ffroujtas & & \\
\hline & & 1460 MA 112 & frujta \\
\hline & & 1472 TC 120 & fruyt[os] \\
\hline & & 1491 Alj 132 & ffrujtos, $2 \mathrm{v}$. \\
\hline & & 1491 Alj 133 & ffrujtos, $2 \mathrm{v}$. \\
\hline & & 1502 MA 137 & ffruytas \\
\hline & & 1519 MA 142 & fruyto \\
\hline & & 1529 MA 148 & fruyta \\
\hline
\end{tabular}

Tabela 6. Variação oi ui na forma historicamente representante de FRŪctu- e seus derivados 
Assim, se considerarmos 1450 como termo ad quem deste fenómeno de variação, contam-se 25 formas etimológicas ${ }^{19}$ desde 1291 e 13 formas com oi desde 1304. Curiosamente, é um documento escrito em Alvorninha (o couto mais rural do mosteiro de Alcobaça) que apresenta ainda as formas já nesta altura antigas ou populares ffroytas e ffroujtas, esta última resultando seguramente da hesitação entre oy e uy, sentida pelo tabelião.

Merece ser salientado o facto de a variante $u i$ ou, monotongada, $u$, serem, atualmente variantes dialetais no galego:

aparecendo a solución -ui- no territorio máis occidental da Coruña, no centro-sul pontevedrés e grande parte do bloque oriental, os resultados con monotongación e con metátese de iode rexístran-se tamén en pequenas áreas do galego oriental (...) FRŪCTA > froita vs. dial. fruita/fruta/frutia (Ferreiro 1999: 80).

\subsection{Ditongo crescente [wa]}

Na forma agua, foi um fenómeno de todos os tempos a antecipação da semivogal [w] para a sílaba tónica, continuando por vezes a manifestar-se (provavelmente apenas por hábito gráfico), nessa posição:

aug[u]a (1337 Alc 27), augoa (1541 Sal 152), augoas (1372 MA 47), augua (1304 Alc 10; 1321 Alc 17, 2 v.; 1419 MA 79; 1453 MA 107), Augua (1391 MA 59), a[u]guas (1391 MA 59, 2 v.) e auguoa (1541 Sal 152, 2 v.).

Formas deste tipo ocupam $81 \%$ do total de ocorrências do nosso corpus, contra $19 \%$ da forma agua (1345 MA 33; 1409 MA 72; 1447 Alj 101). É essa frequência, não só no corpus em análise como na colecção HGP (Maia 1997²: 643), que justifica naturalmente a vitalidade deste fenómeno na linguagem popular portuguesa.

Pelo contrário, a tendência (igualmente popular) de simplificar esse ditongo na forma (a)guardar e derivadas, registada atualmente na língua portuguesa e no galego, não se encontra significativamente representada nos documentos desta coleção, eventualmente por se tratar de uma forma que apenas surge nas fórmulas notariais. Os exemplos que é possível registar não excedem cerca de $10 \%$ do total de ocorrências, situando-se maioritariamente no período compreendido entre 1350 e $1363^{20}$ :

ágardar (1304 Alc 10, 2 v.; 1356 MA 41), agardar (1363 MA 45), gardando (1350 AM 36; 1356 MA 41; 1359 MA 42; 1362 MA 43) e gardardes (1356 MA 41; 1362 MA 43).

De modo completamente isolado, viria a surgir mais tardiamente a forma garda na expressão "pera lua garda" (1526 Ped 145), contida num instrumento de posse. Idêntica percentagem (9\%) corresponde às formas mẽga (1350 AM 36) e mĩga (1410 MA 73), que não ultrapassam a primeira década do século XV, eventualmente pelo facto de esta forma constar das expressões típicas das fórmulas notariais ("que nõ mĩgue per mĩga de benfecturja"). Mais frequentes são formas do tipo cãto 'quanto' (1434 SC 91), qaaes (1433 Ped 90, 2 v.) e cãdo, esta última registada apenas em textos tardios (1485 MA 128; 1487 PP 129). Foi, eventualmente, a consciência desta redução que fez nascer a forma híbrida, também tardia: quayndo (1479 MA 124).

A avaliar pela frequência com que surge nos documentos, a variante simplificada deve ter sido um fenómeno da língua oral, tal como ainda atualmente subsiste na linguagem popular de Norte a Sul de Portugal, embora, segundo Maia (1997²: 642), com mais vitalidade na área do falar minhoto e em galego ${ }^{21}$.

\footnotetext{
${ }^{19} \mathrm{Em}$ alguns casos, /u/ encontra-se representado por <o >: frotificarõ (1304 Alc 10), frotifiguedes (1375 MA 48) e ffrotiuigalfe (1315 Alj 15), tendo sido, de igual modo, contabilizadas no grupo das formas etimológicas.

${ }^{20}$ Estes dados obrigam, portanto, a corrigir a cronologia apontada por Leite de Vasconcelos, segundo o qual este fenómeno aparece "já em manuscritos dos séculos XVI e XVII do Minho" (Maia 1997²: 642, nota 1).

${ }^{21} \mathrm{Na}$ verdade, ainda na década de 90 do século XX, ouvimos frequentemente, numa localidade do distrito português de Aveiro (concelho de Anadia), as formas cando 'quando' e canto 'quanto' (pop.) a falantes de gerações mais antigas, com um grau de instrução praticamente nulo. Cremos que se tratou de uma variante de feição diastrática e não, propriamente, dialetal.
} 


\section{Conclusões}

\section{i. Ditongos au e ai}

Para além de terem conhecido a evolução de tipo culto (com manutenção do ditongo), algumas palavras da linguagem jurídica com ditongo latino Au conheceram igualmente a evolução de tipo popular, nos séculos XIV e XV. Assim, outoridade/outorjdade e outor constituem registos "desviantes", mas que deveriam ser comuns na linguagem oral dos tabeliães. Quando, na mesma palavra, existe um u, registou-se frequentemente a monotongação de au primário em a: claufula e clafula rivalizaram durante o período medieval, apenas se estabelecendo definitivamente a primeira, a partir da década de 80 do século $\mathrm{XV}$, eventualmente depois de soprarem na cultura portuguesa os ventos do italianismo.

Quando o ditongo au é secundário, resultante da vocalização em $u$ do primeiro elemento do grupo -CT-, o tratamento mais comum foi a sua manutenção mas houve igualmente uma tendência para o seu fechamento, no século XIV (ouçõ, por exemplo).

$\mathrm{Na}$ atual forma contrato (no século XV com a variante contrayto, num documento), a monotongação deve ter sido posterior à Idade Média, pois nunca se regista ao longo do período estudado. Uma pista para o estabelecimento dessa cronologia poderá ser a forma tardia (eventualmente, semiculta) tratou, de 1565.

Nas palavras originariamente terminadas em -ARIU, O resultado mais frequente nos textos da região portuguesa analisada é a atração da semivogal para junto da sílaba tónica: notayro, vigairo, contrayro, ordenayro, são alguns exemplos. Mantém-se a terminação em alguns nomes de cargos ou profissões (comendatario, secretarjo) bem como nas variantes gráficas do adjetivo necellario.

Um dos ditongos formados ao longo da história da língua portuguesa particularmente importante para fins de periodização diz respeito ao que resultou da atração da semivogal [j] da forma de Presente do conjuntivo de sabham (< SAPĨANT) para a sílaba tónica, formando com a vogal dessa sílaba o ditongo decrescente ai (Saibam). Essa atração verificou-se, no corpus em apreço, volvido o $1^{\circ}$ quartel do século XV. O mesmo fenómeno de atração pode observar-se na forma elcaybar 'trocar' ( $<{ }^{*}$ EXCAMBIĀRE) e no nome deverbal elcaybo, que se verificou já no $3^{\circ}$ quartel do mesmo século.

\section{ii. Ditongos ei e ou}

É extremamente interessante a evolução registada na forma de origem árabe aldeya (s. XIV) > aldea (s. XV, 1450, 2 v.) > aldeia (s. XVI) no corpus em estudo, particularmente se pensarmos que aldea é a forma típica do galego. A mudança teve, contudo, outra direção em meyado e meyo (ss. XIV e XV), de origem latina, pois a partir de finais do século XIV e até ao século XVI prevalecem as formas meo e mea.

A monotongação de ei, documentada neste corpus desde 1363, deve ter encontrado um contexto propício quando o ditongo vem seguido de fricativa palatal surda (graficamente, $x<$ -x- ou İ +-sc-), mas também de vibrante simples alveolar, ou seja, sons articulatoriamente muito próximos da semivogal para sustentar a sua manutenção. Entre os meados do século XIV e o primeiro quartel do século XVI a monotongação regista-se em 21 abonações: lexar (1362, 1363 e 1419), ferero, camarero (1402), pexe(s) (1515, 8 v.), Viera (1515), meo (1392, 1472, 1505), mea $(1528,2$ v.) e aldea (1453, 2 v.).

Quanto à monotongação de ou, atualmente aceite pela norma, desde finais do século XIII, mas mais intensamente a partir do último quartel do século XIV, o nosso corpus apresenta inúmeras manifestações dessa tendência, de origem rústica ou popular.

\section{iii. Variação oi/ui}

A análise do nosso corpus revela que se verificou, ao longo do século XIV, a propagação analógica do ditongo oi a formas que continham etimologicamente ui (FRÜCTU- e seus derivados, por exemplo), criando a variação do tipo fruito/froito, cujo termo ad quem foi 1450, em proveito da forma etimológica fruito, dialetal no galego. 
iv. Antecipação de vogal (auga) e simplificação de [wa]

$\mathrm{Na}$ forma agua, verificou-se, ao longo do leque cronológico abrangido pelo presente estudo, a antecipação da semivogal u para a sílaba tónica $(a u g<u>a)$. Do mesmo modo, simplificou-se o ditongo na forma (a)guardar e derivadas, tal como acontece hoje na língua portuguesa e no galego. Formas como garda, mẽga, mĩga, cãto, qaaes e cãdo atravessam os documentos desta coleção, tendo sido eventualmente a consciência desta redução que fez nascer a forma híbrida, já tardia, quayndo (1479 MA 124).

Pelo que foi exposto, é legítimo afirmar que, se a língua tivesse seguido, naturalmente, o seu rumo, sem o espartilho nivelador e normativo exercido pela Corte e pelos colégios monásticos portugueses do Centro-litoral, ou, eventualmente, sem os juízos de valor que os gramáticos lhe foram impondo ao longo dos séculos, formas como froito, aldea, gardar, auga ou Tareija estariam ainda vivas numa língua que não hesitaríamos em chamar "galego-português".

\section{REFERÊNCIAS BIBLIOGRÁFICAS}

Barbosa, Jorge Manuel de Morais Gomes (1958): Cronica de Castela (ms. 8817 da Biblioteca Nacional de Madrid). Elementos para o estudo linguístico. Texto (Fernando I - Afonso VI). Volume I (Introdução e elementos para o estudo linguístico). Vol. II (Texto). Vol. III (Glossário). Dissertação de licenciatura em Filologia Românica, inédita. Faculdade de Letras, Universidade de Lisboa.

Boullón Agrelo, Ana Isabel (1999): Antroponímia medieval galega (ss. VIII-XII). Tübingen: Max Niemeyer Verlag.

Cardeira, Esperança (2005): Entre o Português Antigo e o Português Clássico. Lisboa: Imprensa Nacional - Casa da Moeda.

Cardeira, Esperança / Maria Alice Fernandes (1997): "Aspectos do português algarvio na transição do século XIV para o XV", em Ivo Castro (ed.), Actas do XII Encontro Nacional da Associação Portuguesa de Linguística (Braga-Guimarães, 30 de Setembro a 2 de Outubro de 1996), vol. II. Lisboa: Associação Portuguesa de Linguística, 55-68.

Carvalho, Maria José (1999): "A alomorfia no plural dos nomes de lexema em -l: um estudo de morfologia histórica portuguesa", em Ana Cristina Macário Lopes / Cristina Martins (orgs.), Actas do XIV Encontro Nacional da Associação Portuguesa de Linguística, vol. I. Braga: Associação Portuguesa de Linguística, 265-281.

Carvalho, Maria José (2000): "O morfema -des na história da língua portuguesa. Uma abordagem segundo a metodologia da Sociolinguística histórica", em Annick Englebert / Michel Pierrard / Laurence Rosier / Dan Van Raemdonck (eds.), Actes du XXIle Congrès International de Linguistique et de Philologie Romanes (23-29 juillet 1998), vol. II. Tübingen: Max Niemeyer Verlag, 65-74.
Carvalho, Maria José (2006): Documentação medieval do mosteiro de Santa Maria de Alcobaça (sécs. XIII-XVI). Edição e estudo linguístico. Dissertação de doutoramento apresentada à Faculdade de Letras da Universidade de Coimbra [O corpus incluído nesta tese foi publicado em Verba, Anexo 74].

Carvalho, Maria José (2011): "From Etimology to Cognitive Sociolinguistics. A Case-Study from European Portuguese", em Augusto Soares da Silva / Amadeu Torres / Miguel Gonçalves (orgs./ eds.), Línguas Pluricêntricas. Variação Linguística e Dimensões Sociocognitivas / Pluricentric Languages. Linguistic Variation and Sociocognitive Dimensions. Braga: Aletheia, 353 - 364.

Carvalho, Maria José (2015a): "Sobre as origens dos valores de /e/ átono em posição medial no Português europeu e brasileiro", Revista Galega de Filoloxía 16, 43-73. doi: 10.17979/ rgf.2015.16.0.1378. [27/12/2017]

Carvalho, Maria José (2015b):"Sobre as origens de [u] átono no Português europeu contemporâneo: variação, mudança e dimensões sociocognitivas", Diacrítica. Série Ciências da Linguagem 29/1, 171-202. http://www.scielo.mec.pt/scielo. php?script=sci_arttext\&pid= http://www.scielo.mec.pt/scielo.php?script=sci_arttext\&pid=S0807-89672015000100007\&lng [27/12/ 2017]

Carvalho, Maria José (2017): Documentação medieval do mosteiro de Santa Maria de Alcobaça. Edição, com introdução e notas de aparato crítico. (= Verba, Anexo 74). Santiago de Compostela: Servicio de Publicacións e Intercambio Cientifico: http://dx.doi.org/10.15304/9788416533817 [27/12/2017].

Castro, Ivo (com a colaboração de Rita Marquilhas e José León Acosta) (1991): Curso de história da língua portuguesa. Lisboa: Universidade Aberta. 
Ferreiro, Manuel (1999): Gramática Histórica Galega. I. Fonética e Morfosintaxe. Santiago de Compostela: Edicións Laiovento.

Kabatek, Johannes (2001): “¿Cómo investigar las tradiciones discursivas medievales? El ejemplo de los textos jurídicos castellanos", em Daniel Jacob / Johannes Kabatek (orgs.), Lengua medieval y tradiciones discursivas en la Península Ibérica: descripción gramatical - pragmática histórica - metodologia. Frankfurt am Main / Madrid: Iberoamericana Vervuert, 97-132 (Linguística Iberoamericana, 12).

Lorenzo, Ramón (1977): La traducción gallega de la Crónica General y de la Crónica de Castilla, vol II (Glosario). Ourense: Instituto de Estudos Orensanos "Padre Feijoo".
Maia, Clarinda (1997²): História do galego-português. Estado linguístico da Galiza e do Noroeste de Portugal desde o século XIII ao século XVI. Lisboa: FCG/JNICT.

Nunes, José Joaquim (1989): Compêndio de Gramática Histórica Portuguesa (Fonética e Morfologia). Lisboa: Clássica Editora.

Teyssier, Paul (1980): Histoire de la langue portuguaise. Paris: Klincksieck.

Veiga Rodríguez, Alexandre (1986): "Notas sobre algúns procesos reductivos de ditongos decrescentes en galego", Verba 13, 301-311 https://minerva.usc.es/xmlui/bitstream/handle/10347/4900/pg_303-314_verba13.pdf?sequence $=1$ \&isAllowed $=y[27 / 12 / 2017]$. 